\title{
STUDY ON THE COASTLINE CHANGE OF JIAOZHOU BAY BASED ON HIGH RESOLUTION REMOTE SENSING IMAGE
}

\author{
Zhu Hui ${ }^{1, *}$, Xing Baiyang ${ }^{1}$, Ni Shaoqi ${ }^{2}$, Wei Pan $^{1}$ \\ ${ }^{1}$ Shandong University of Science and Technology, Qingdao 266590, China-364450204@qq.com \\ ${ }^{2}$ China Maritime Supervision Beihai Air Detachment, Qingdao 266061, China
}

KEY WORDS: Jiaozhou Bay, Coastline, Increase, Decrease, Rate

\begin{abstract}
:
In recent years, with the rapid development of the Jiaozhou Bay area of Qingdao, the influence of human activities on the coastline of Jiaozhou Bay is becoming more and more serious. Based on the high resolution remote sensing image data of 10 periods from 2001 to 2017 in the Jiaozhou Bay area, and combined with the data of on-the-spot survey and expert knowledge, this paper have completed the interpretation and extraction of coastline data of each year, and analyzed the distribution, size, rate of change, and trend of the increase and decrease of the coastal area of Jiaozhou Bay in different time periods, combined with the economic construction and the marine hydrodynamic environment of the region to analyze the reasons for the change of the coastline of Jiaozhou Bay. The results show that the increase and reduction of the coastal area of Jiaozhou Bay was mainly affected by human activities such as sea reclamation and marine aquaculture, resulting in a gradual change in the rate of increase and decrease with human development. For coastal advance part,2001-2013, the average increase rate on the coastal area of Jiaozhou Bay was $2.30 \mathrm{~km}^{2} / \mathrm{a}$, showing a trend of rapid growth, 2013 2017 the average increase rate of $0.53 \mathrm{~km}^{2} / \mathrm{a}$, and the growth rate slowed down. For coastal retreat part, 2001-2013, the average decrease rate was $2.58 \times 10^{-3} \mathrm{~km}^{2} / \mathrm{a} .2013-2014$, the decrease rate reached a peak value of $1.11 \mathrm{~km}^{2} / \mathrm{a} .2014-2017$, the average decrease rate was $0.14 \mathrm{~km}^{2} / \mathrm{a}$. The decrease rate shows a trend of increasing first and then slowing down.
\end{abstract}

\section{INTRODUCTION}

With the country's increasing emphasis on the ocean, Qingdao has developed rapidly as a coastal city in recent years. Jiaozhou Bay is the largest bay in Qingdao, and the development of the Jiaozhou Bay area is of crucial to Qingdao. Therefore, it is highly valued by the Qingdao Municipal Government. At present, the new pattern of building the 'three bays and three cities' proposed by the Qingdao Municipal Government is still centered on Jiaozhou Bay. In recent years, the rapid economic development of Jiaozhou Bay area, the sea reclamation activities such as the construction of urban areas have greatly changed the contour and area of the coastal zone and the bay. The impact of marine aquaculture and other activities surrounding the sea on the changes in the sea area of the Jiaozhou Bay have also gradually increased. Meanwhile, with a total area of Jiaozhou Bay is shrinking, gradually decrease in tidal influx, the flow rate decreases, the bay water exchange capacity weaker. These changes in turn affect the coastline of Jiaozhou Bay.

Based on the chart, Hongxia Chen et al. analyzed the changes in the coastline and water depth of Jiaozhou Bay. Chunxia Zhou et al. studied the attributes and position changes of Jiaozhou Bay shoreline for nearly 150 years through multi-temporal satellite remote sensing combined with historical charts and water depth data. Lijie Ma et al. used the charts and topographic maps to extract the five coastlines of Jiaozhou Bay and analyzed the sea area changes in the past 150 years. Based on Landsat-5 TM

\footnotetext{
* Corresponding author
} 
The International Archives of the Photogrammetry, Remote Sensing and Spatial Information Sciences, Volume XLII-3, 2018 ISPRS TC III Mid-term Symposium “Developments, Technologies and Applications in Remote Sensing”, 7-10 May, Beijing, China

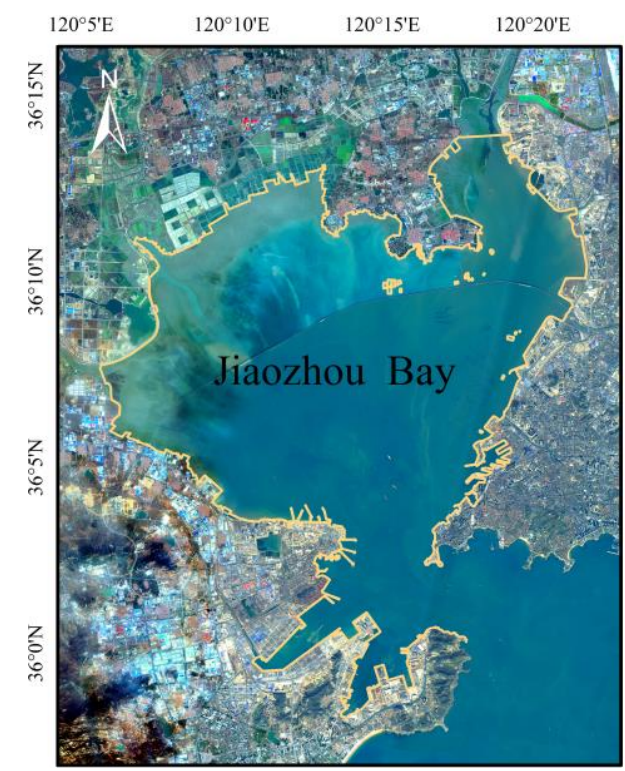

Figure 1 The study range and its coastline of Jiaozhou Bay

\begin{tabular}{ccc}
\hline Time & Spatial Resolution & Type \\
\hline 2001 & $15 \mathrm{~m}$ & Landsat-7 \\
2007 & $1 \mathrm{~m}$ & $\begin{array}{c}\text { Airborne Remote } \\
\text { Sensing }\end{array}$ \\
& & SPOT-5 \\
2010 & $2.5 \mathrm{~m}$ & SPOT-5 \\
2011 & $2.5 \mathrm{~m}$ & SPOT-5 \\
2012 & $2.5 \mathrm{~m}$ & Airborne Remote \\
2013 & $0.5 \mathrm{~m}$ & Sensing \\
& & GF-1 \\
2014 & $2 \mathrm{~m}$ & GF-2 \\
2015 & $1 \mathrm{~m}$ & GF-2 \\
2016 & $1 \mathrm{~m}$ & GF-2 \\
2017 & $1 \mathrm{~m}$ & \\
\hline
\end{tabular}

Table 1 Introduction of remote sensing image from 2001 to 2017

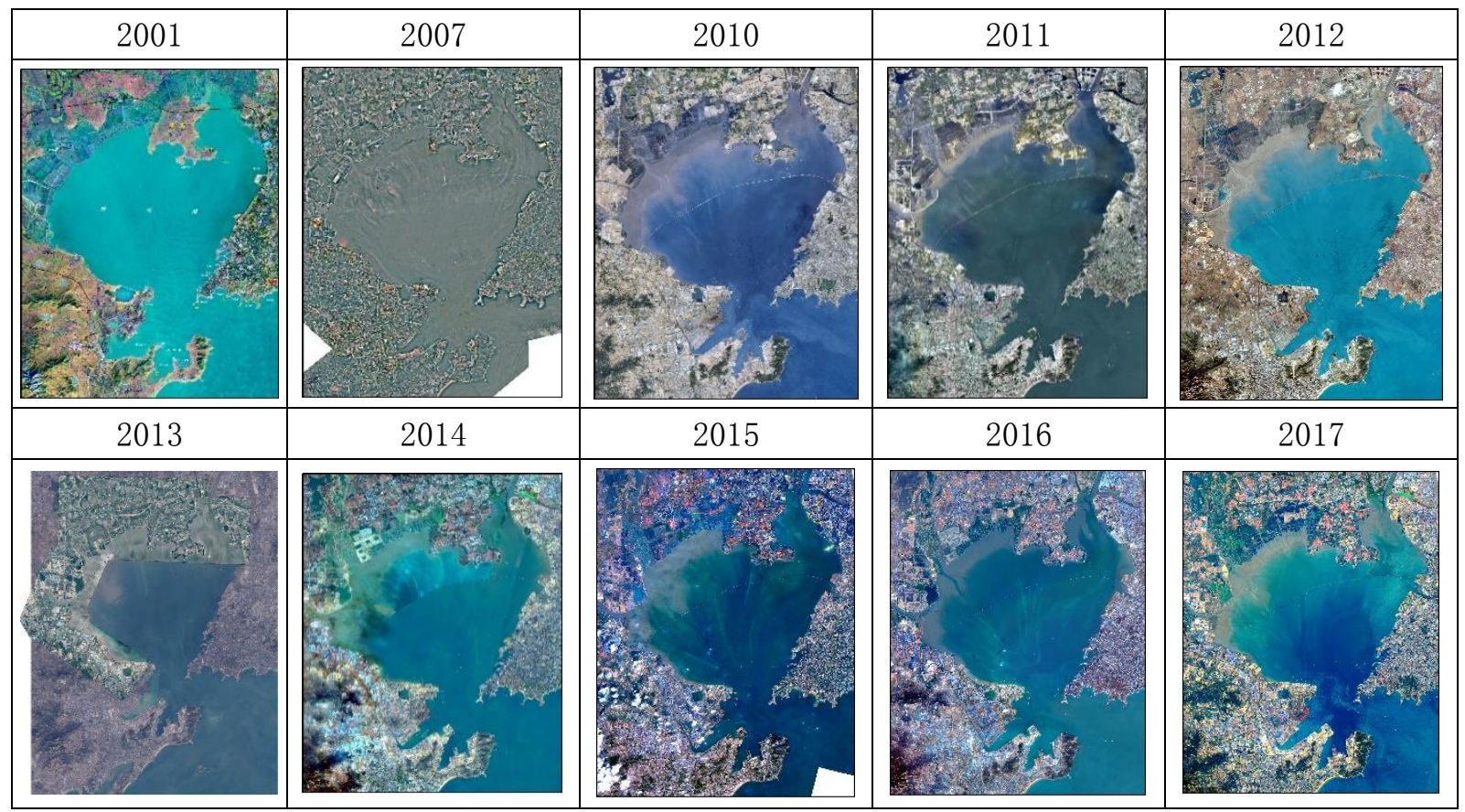

Figure 2 Remote sensing images of Jiaozhou Bay from 2001 to 2013

remote sensing images which were precisely corrected and obtained from 1987 to 2006, Xiaomin Ye et al. calculated the fractal dimensions of the coastline of the Jiaozhou Bay by means of a gridding method, and analyzed the reasons for the change of the fractal dimension of the shoreline. In recent years, the coastline of Jiaozhou Bay has been changing, and the change of increase and decrease area is more complicated. However, there is no accurate research based on high resolution remote sensing image and its trend. Therefore, studying the changes in the coastline of Jiaozhou Bay in recent years, grasping the factors influencing the coastline change, and predicting the trend of change, can provide basic scientific evidence for improving the economic benefits of the Jiaozhou Bay area and the sustainable use of marine resources.

\section{DATA AND METHODS}

\subsection{The Study Range and Data}

This paper collected 10 high-resolution remote sensing images 
covering the Jiaozhou Bay area. The imaging time was 20012017 , and the coverage was $120^{\circ} 05^{\prime} \sim 120^{\circ} 25^{\prime} \mathrm{E}, 35^{\circ} 55^{\prime} \sim$ $36^{\circ} 20^{\prime} \mathrm{N}$ (Figure 1, Figure 2). These 10 remote sensing images have been precisely corrected and the WGS 84 coordinate system and the UTM-51N projection have been adopted. Data sources include Landsat-7, SPOT-5, GF-1, GF-2 and Airborne Remote Sensing. Detailed information is shown in Table 1.

\subsection{Coastline Extraction}

2.2.1 Coastline Extraction Principle: The Jiaozhou Bay coastline consists of bedrock shoreline, sandy shoreline, silt shoreline and artificial shoreline. The sea cliffs on the bedrock coast are steep, covered with vegetation, with clear boundaries between sea and land, and with twisting coastlines. Sandy coasts are generally flat. In remote sensing images, the location of sandy coastlines should be taken in the upper limit of the beach ridge footprint. The silt shoreline is located on the silt shore and has a wide beach. In remote sensing images, the place where the lush vegetation and sparseness are significantly different is the location of the silt shoreline. The artificial coastline formed by sea reclamation, dam, port, and salt fields and aquaculture ponds has obvious interpretation signs. In remote sensing images, the outer edge of the outline is the coastline location.

The principle of determining the coastline at the estuary is to take the intersection of the shoreline on both sides of the estuary and the banks of the estuary entrance to the sea, and then connect them as the estuary coastline. There are many dikes in Jiaozhou Bay, and some of the dikes extend into the sea for a long distance. Since this paper mainly studies the change of increase and decrease area in coastal areas, the dam body is also extracted as it is. The line between Tuandaotou and Xuejiadao-Jiaozishi is the dividing line of Jiaozhou Bay sea area.

2.2.2 Coastline Extraction Method: ArcGIS is used as a platform to extract information of coastlines in different periods using human-computer interaction method. The detailed technical route is as follows: (1) With reference to 2001 remote sensing images, the 2001 coastline was extracted. (2) When the 2007 coastline was extracted, the 2001 coastline was first loaded onto the 2007 remote sensing image, and only the changed parts were modified to obtain the 2007 coastline. (3) Extract the coastline from 2010 to 2017 in the same way. A total of 10 coastlines were obtained. The advantage of this method is to ensure that the unchanging coastline segment has the same geographical location at different times, and the coastline position error will not be caused by the deviation of the image itself. In this way, the coastline is only the waterside line, and it is necessary to calibrate the waterside line according to on-thespot survey and expert knowledge, to obtain the coastline of 10 periods of Jiaozhou Bay. Figure 3.

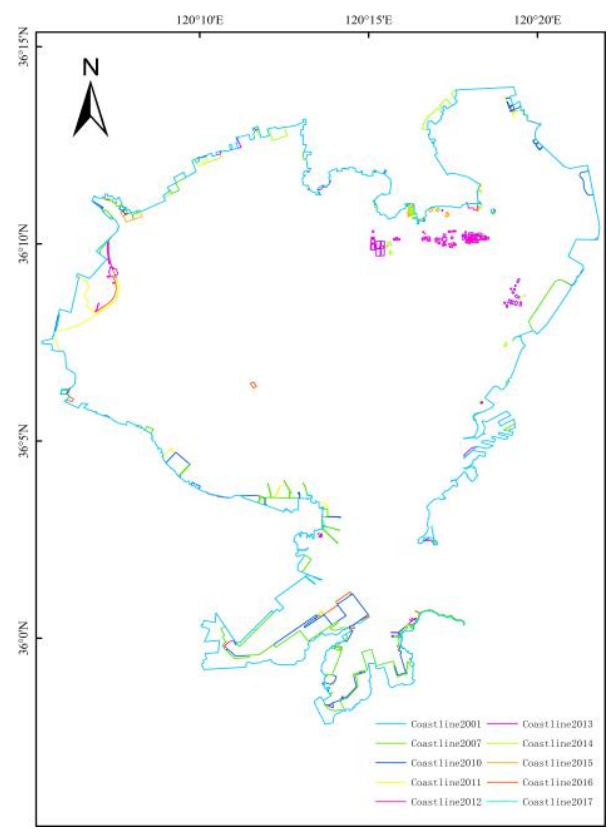

Figure 3 Jiaozhou Bay Coastline 2001-2017

\subsection{Coastal Increase and Decrease Area Extraction}

\subsubsection{Coastal Increase and Decrease Area Extraction}

Principle: The two coastlines in different years are loaded at the same time, the overlapping part is the unchanging bank, and the non-overlapping part is the change coast. Distinguish and mark this area as increase or decrease according to the year of the front and rear boundary of the change coast. Jiaozhou Bay is a semienclosed harbor with islands and marine aquaculture facilities in the bay. In order to not affect the results of the study, the extraction process requires the use of an auxiliary line. The auxiliary line is a line that is on the outside of the Jiaozhou Bay coastline and closed with the coastline.

\subsubsection{Coastal Increase and Decrease Area Extraction Method:}

ArcGIS is used as a platform to extract the coast increase and decrease areas using human-computer interaction method. The detailed technical route is as follows: (1) Establish an auxiliary line outside the Jiaozhou Bay coastline and form a closed line element with the extracted 2001 coastline. (2) Convert all closed 
The International Archives of the Photogrammetry, Remote Sensing and Spatial Information Sciences, Volume XLII-3, 2018

ISPRS TC III Mid-term Symposium “Developments, Technologies and Applications in Remote Sensing”, 7-10 May, Beijing, China

\begin{tabular}{lcccccc}
\hline & $\begin{array}{c}\text { Increase Area } \\
\left(\mathrm{km}^{2}\right)\end{array}$ & $\begin{array}{c}\text { Decrease Area } \\
\left(\mathrm{km}^{2}\right)\end{array}$ & $\begin{array}{c}\text { Average Annual } \\
\text { Increase Rate } \\
\left(\mathrm{km}^{2} / \mathrm{a}\right)\end{array}$ & $\begin{array}{c}\text { Average Annual } \\
\text { Decrease Rate } \\
\left(\mathrm{km}^{2} / \mathrm{a}\right)\end{array}$ & $\begin{array}{c}\text { Average Rate } \\
\text { of Change in } \\
\text { Increase Rate }\end{array}$ & $\begin{array}{c}\text { Average Rate } \\
\text { of Change in } \\
\text { Decrease Rate }\end{array}$ \\
\hline $2001-2007$ & 13.336 & 0.035 & 2.223 & 0.006 & & \\
$2007-2010$ & 5.217 & 0.198 & 1.739 & 0.066 & $-21.8 \%$ & $1000 \%$ \\
$2010-2011$ & 3.079 & 0.038 & 3.079 & 0.038 & $77.1 \%$ & $-42.4 \%$ \\
$2011-2012$ & 1.322 & 0.053 & 1.322 & 0.053 & $-57 \%$ & $39.5 \%$ \\
$2012-2013$ & 3.135 & 0.181 & 3.135 & 0.181 & $137.1 \%$ & $241.5 \%$ \\
$2013-2014$ & 0.851 & 1.105 & 0.851 & 1.105 & $-72.9 \%$ & $510.5 \%$ \\
$2014-2015$ & 0.373 & 0.428 & 0.373 & 0.428 & $-56.2 \%$ & $-61.3 \%$ \\
$2015-2016$ & 0.781 & 0.292 & 0.781 & 0.292 & $109.4 \%$ & $-31.8 \%$ \\
$2016-2017$ & 0.112 & 0.121 & 0.112 & 0.121 & $-85.7 \%$ & $-58.6 \%$ \\
\hline
\end{tabular}

Table 2 Increase and decrease area statistics

line features to polygon features. (3) Extract polygon features of other years in the same way. (4) By the Overlay Analysis between the obtained polygon elements, the area of increase and decrease changes between any two years can be obtained.

\subsection{Sea Area Extraction}

2.4.1 Sea Area Extraction Principle: The area of sea area in this paper refers to the area covered by seawater, excluding the islands and mariculture facilities in Jiaozhou Bay.

2.4.2 Sea Area Extraction Method: ArcGIS is used as a platform to extract sea area using human-computer interaction method. The detailed technical route is as follows: (1) Connect the two ends of the coastline, close it and calculate its area. (2) Using the extracted increase and decrease areas, calculate the area occupied by islands and mariculture facilities in Jiaozhou Bay. (3) The total area of sea area minus the area occupied by islands and marine aquaculture facilities can obtain the actual sea area.

\section{RESULT AND DISCUSSION}

\subsection{Temporal and Spatial Variations of Increase and Decrease Regions}

2001-2007, the increase area was $13.336 \mathrm{~km}^{2}$, the average annual increase area was $2.223 \mathrm{~km}^{2} / \mathrm{a}$, the decrease area was $0.035 \mathrm{~km}^{2}$, and the average annual decrease area was only $5.8 \times 10^{-3} \mathrm{~km}^{2} / \mathrm{a}$. Increase areas are mainly concentrated on the eastern side of Cangkou waterway on the east bank of Jiaozhou Bay and the Huangdaoqian Bay and Haixi Bay on the south bank, and a small amount on the west bank. The visual interpretation of remote sensing images shows that the sea reclamation in the east coast is mainly used for real estate development, and the reclamation in the south bank is mainly used for the construction of port terminals and Huangdao oil depot. A small amount of aquaculture ponds added to the west bank. Decrease areas are distributed on the north and west bank, including two shorelines that are eroded by seawater, and the cleanup of a small number of mariculture facilities. Figure 4.

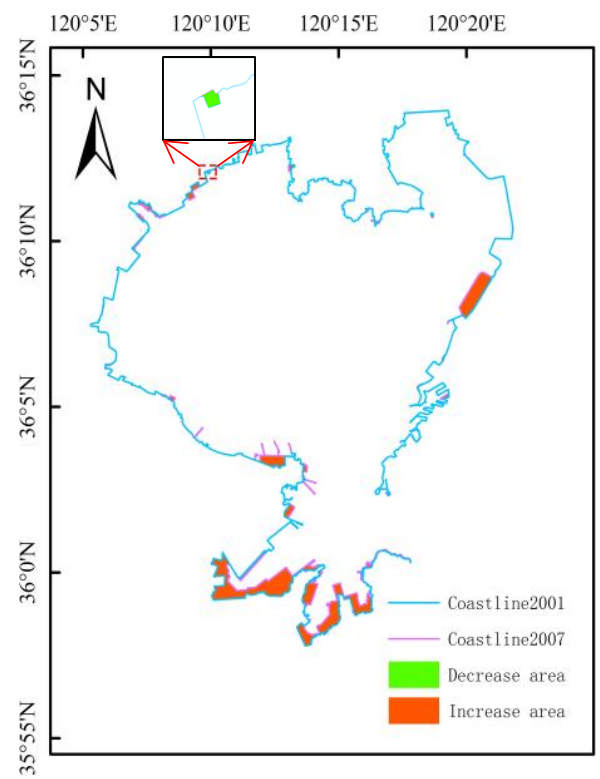

Figure 4 Increase and Decrease in Jiaozhou Bay 2001-2007

2007-2013, the area of increase was $12.356 \mathrm{~km}^{2}$, the average annual increase area was $2.059 \mathrm{~km}^{2} / \mathrm{a}$, the decrease area was 0.07 
$\mathrm{km}^{2}$, and the average annual decrease area was only $11.6 \times 10^{-3}$ $\mathrm{km}^{2} / \mathrm{a}$. The average siltation rate in 2007-2013 was lower than 2001-2007, but the annual average increase area changed greatly and the increase rate was still relatively fast. The increase areas are mainly distributed in the south of the Loushan River estuary in the northeast of Jiaozhou Bay, between the Yanghe River estuary in the southwest and the Dagu River estuary, in the east of the Huangdaoqian Bay and the east of the Haixi Bay, and in the south of the Tuandao. There are also more new aquaculture facilities such as cages and floating rafts in Jiaozhou Bay. The aquaculture ponds in the west bank continued to increase, but they accounted for a small proportion of the siltation area. The decrease area is mainly distributed in the natural shoreline of the south bank. During this period, due to the artificial modification, the shoreline has experienced a phenomenon of land receding. Figure 5.

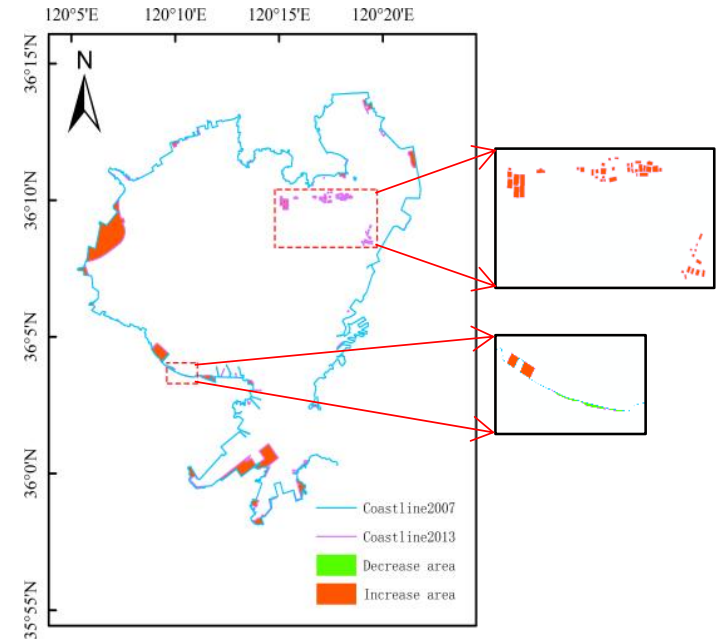

Figure 5 Increase and decrease in Jiaozhou Bay 2007-2013

2013-2017, the area of increase was $1.64 \mathrm{~km}^{2}$, the average annual increase area was $0.41 \mathrm{~km}^{2} / \mathrm{a}$, the decrease area was 1.47 $\mathrm{km}^{2}$, and the average annual decrease area was $0.367 \mathrm{~km}^{2} / \mathrm{a}$. The average siltation rate in 2013-2017 has slowed down significantly compared with the previous two periods, but the relative annual variation during this period is large; the average annual decrease rate has accelerated significantly, reaching 32 times the previous period. The siltation is mainly due to the small increase in aquaculture ponds on the west bank of Jiaozhou Bay and sea reclamation on the eastern side of Huangdaoqian Bay. The decrease in area was mainly due to the reduction of aquaculture ponds on the east coast of Hongdao Island and the cleanup of aquaculture facilities such as cages and floating rafts in Jiaozhou Bay. Figure 6.
2001-2013, the annual average of Jiaozhou bay increase rate faster, but also makes great change in adjacent period, 2007 -

2010 average annual rate of change was $21.8 \%$ lower than 2001 -

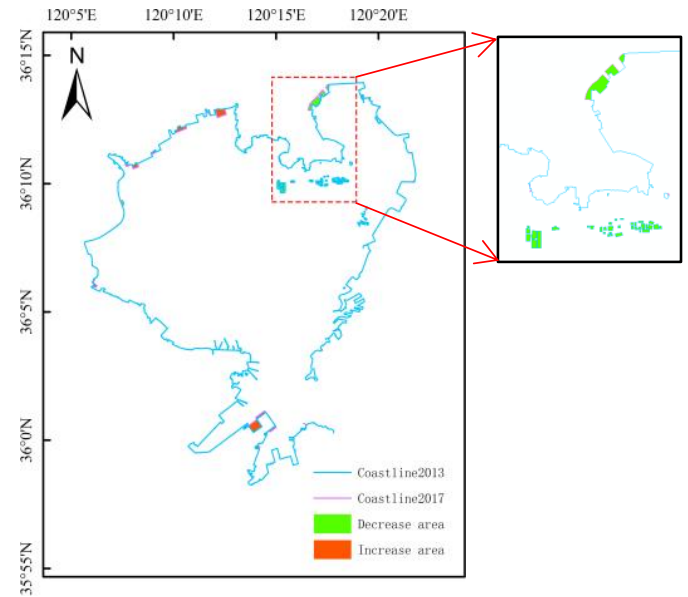

Figure 6 Increase and Decrease in Jiaozhou Bay 2013-2017

2007, and 2010-2011 average annual rate of more than 20072010 was up $77.1 \%$, especially the average annual rate of change in $2012-2013$ has increased by $137.1 \%$ compared with $2011-$ 2012. Since 2013, although the average annual change rate of 2015-2016 has been greatly changed than that of 2014-2015 years, the area of increase is small and the total amount of change is not large.

2001-2007, the average annual decreasing rate of Jiaozhou Bay coast was relatively low, and the annual average decrease area has been increased by 10 times in 2007-2010, and the average annual decrease area only increased by $0.06 \mathrm{~km}^{2}$. The Jiaozhou Bay area carried out a large-scale marine aquaculture management work in 2012. Many cages, floating rafts and other aquaculture facilities in the Jiaozhou Bay and the coastal aquaculture ponds were cleaned up and rectified. Therefore, in 2012-2014, the average annual decrease area and the interannual change increased synchronously. With the continuous advancement of the governance of 2014-2017, the area to be treated has gradually decreased, and the inter-annual changes have also dropped below $65 \%$.

The flow field in Jiaozhou Bay has an important influence on the increase and decrease areas. The northern coast of Jiaozhou Bay, with a wide distribution of shoals and relatively low flow rate, has a natural advantage for marine aquaculture. The velocity of the Huangdaoqian Bay and Haixi Bay flow fields on the south bank of Jiaozhou Bay is low (Figure 7). The water exchange capacity is weak, and solid materials are easily deposited, 
causing the surrounding area to become the main area for sea reclamation. On the other hand, the change of the shoreline also changed the hydrodynamic environment in Jiaozhou Bay, which resulted in a decrease in the flow rate of the Jiaozhou Bay and a further weakening of the water exchange capacity, which reduced the intensity of the material exchange between the bay and the open sea and aggravated riverbed deposition in the estuary. The sedimentation of the riverbed reaches a certain level, and humans have begun to construct a seawall dam for economic activities. Human activities in turn will affect the hydrodynamic environment in Jiaozhou Bay.

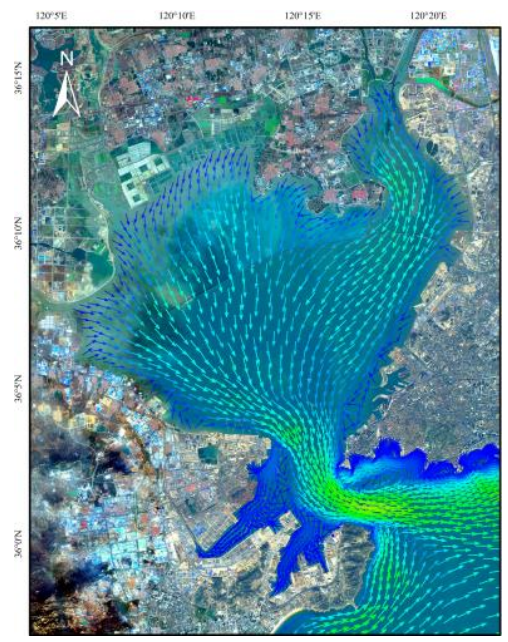

Figure 7 Jiaozhou Bay flow field diagram

\subsection{Spatial and Temporal Variation of Sea Area}

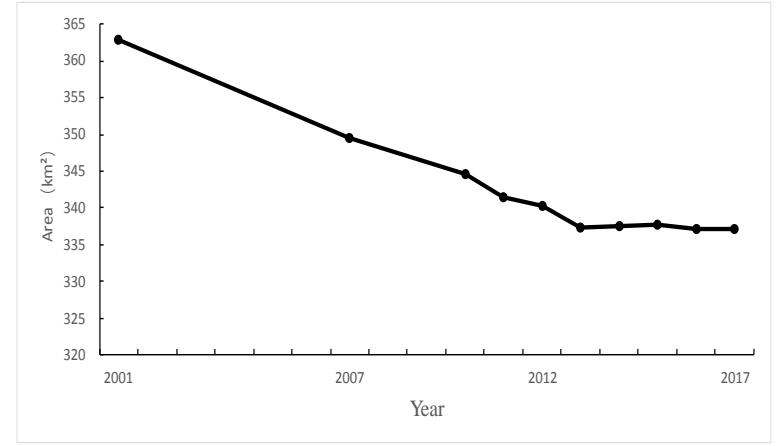

Figure 8 Area changes of Jiaozhou Bay in recent year

From 2001 to 2017, the sea area of the Jiaozhou Bay showed a decreasing trend (Figure 8). From 2001 to 2013, the decrease rate was rapid. The area decreased from $362.9 \mathrm{~km}^{2}$ to $337.3 \mathrm{~km}^{2}$, and the annual average decrease rate reached $2.13 \mathrm{~km}^{2} / \mathrm{a}$. However, in recent years, the decreasing trend of the area gradually slowed down. From 2013 to 2017, the rate of area reduction was only $0.042 \mathrm{~km}^{2} /$ a. 2013-2014, 2014-2015 and 2016-2017, there has even been a slight increase in sea area. These changes are closely related to the economic development model of the Jiaozhou Bay area. Before 2013, in order to pursue economic benefits and urban expansion, the development of marine aquaculture and continuous sea reclamation has led to a rapid reduction in the sea area of Jiaozhou Bay. Since 2014, with the increasing control over sea reclamation and the increasing emphasis on marine environmental protection, there has been only a slight increase in the area of sea reclamation and marine aquaculture has been strictly regulated, especially the sea cages in the bay have all been cleaned up. Only a small increase in mariculture area in certain areas along the coast.

\section{CONCLUSION}

The results of the study indicate that the changes in the shoreline in Jiaozhou Bay in recent years have obvious phase:

(1)2001-2013, the average increase rate of Jiaozhou Bay was $2.13 \mathrm{~km}^{2} / \mathrm{a}$, showed a rapid increase;2001-2013, the average decrease rate was $2.58 \times 10^{-3} \mathrm{~km}^{2} / \mathrm{a}$, showed a slow decreasing trend. During this period, the economic development of Jiaozhou Bay was in a stage of rapid development. In order to supply land for human activities such as building houses, oil depots, and port, a large-scale sea reclamation project was carried out. At the same time, the development of marine aquaculture also takes up a large number of sea areas. These factors weaken the flow field velocity and water exchange capacity in Jiaozhou Bay, thereby weakening the natural erosion ability of seawater

(2) 2013-2017, the average increase rate of Jiaozhou Bay is 0.53 $\mathrm{km}^{2} / \mathrm{a}$, showed a slow increasing trend. 2013-2014, the decrease rate reaches a peak of $1.11 \mathrm{~km}^{2} / \mathrm{a}$, while the average decrease rate in 2014-2017 falls to $0.14 \mathrm{~km}^{2} / \mathrm{a}$, the decrease rate showed a downward trend. In 2013, the Qingdao Municipal Government issued the "Notice on Cleaning Aquatic Facilities in the Jiaozhou Bay Sea Area', and a large number of mariculture facilities were cleared. The increase of this period mainly comes from sea reclamation, while decrease is mainly due to the cleaning of aquaculture facilities.

(3) The area of the sea is constantly changing with the change of increase and decrease area. 2001-2013, the area of coastal area increased rapidly, resulting in a rapid reduction in sea area. 2013 2017 , the area of eroded areas continued to increase, the growth 
rate of silted areas slowed down, and the area of sea areas showed an alternating phenomenon of increase and decrease.

In summary, human activities and policy regulation in recent years have played a decisive role in the change of coastline in Jiaozhou Bay. The hydrodynamic environment also has an important impact on human activities, indirectly affecting the changes of the coastline. At the same time, the changes in the coastline are constantly changing the hydrodynamic environment. Timely understanding of the changes in the coastline, strengthening monitoring and protection of the marine environment, formulating systematic plans, rationalizing the use of marine resources, and exploring the sustainable development of the Jiaozhou Bay area should be the focus of attention in the future.

\section{REFERENCES}

Chen H.X., Hua F., Liu N., 2009. Study on variability of coastline and water depth of Jiaozhou Bay in recent years. Advances in Marine Science, 27(2), pp. 149-154.

Chen J.R., Chen X.E., 2012. Numerical simulation of the hydrodynamic evolution of the Jiaozhou Bay in the last 70 years. Acta Oceanologica Sinica, 34(6), pp. 30-41.

Ma X.F., Zhao D.Z., Zhang F.S.,2007, An overview of means of withdrawing coastline by remote sensing. Remote Sensing Technology and Application, 22 (4), pp. 575-580.

Suo A.N., Cao K., Ma H.W.,2015. Discussion on classification system of coastline. Scientia Geographica Sinica, 35(7), pp. 933-937.

Wang X.G., Li X.Y., Jia M.M., 2017. Analysis on changes in coastline and reclamation in Dalian from 1975 to 2015. Marine Environmental Science, 36(1), pp. 87-93

Wang Y.L., Yu J.B., Dong H.F., 2012. Spatial evolution of landscape pattern of coastal wetlands in Yellow River Delta. Scientia Geographica Sinica, 32 (6), pp. 717 724.

Zhou C.Y., Li G.X., Shi J.H., 2010. Coastline change of Jiaozhou Bay over the last 150 years. Periodical of Ocean University of China, 40(7), pp. 99-106.
Zhu G.R., Xu X.G., 2012. Annual processes of land reclamation from the sea along the northwest coast of Bohai Bay during 1974. Scientia Geographica Sinica, 32 (8), pp. 1006 1012 